\title{
The (Legal) Pains of Vioxx: Why Product Liability Can Make Products More Dangerous
}

\author{
OMRI BEN-SHAHAR
}

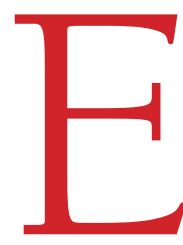
conomists traditionally believe that the more severe is product liability, the greater is the manufacturer's incentive to make its products safe. wharmaceutical liabil sively harsh, leading pharmaceutical companies to choose safety over effectiveness. Are drugs that should stay on the market being withdrawn or not being developed because of the way our liability system works?

I have begun to fear that this traditional logic is misguided. It appears that the more liability associated with a product, the more

Omri Ben-Shahar is the Kirkland and Ellis Professor of Law and Economic at the University of Michigan law School and the Director of the John M. Olin Center for Law and Economics at Michigan. http://www.umich.edu/ omri likely pharmaceutical companies are to leave risky products on the market and invest less in determining their risks.

Compare the experiences of two pain drugs in the same family: Vioxx made by Merck and Celebrex made by Pfizer. After Merck withdrew Vioxx from the market, it was inundated with litigation. Pfizer appears to have learned Merck's lesson and adopted a do-little-or-nothing strategy. Instead of a recall, Pfizer silently adjusted its warnings and instructions to physicians. Pfizer did far less than Merck in terms of consumer protection; yet, at least thus far, Pfizer is facing nothing that resembles Merck's liability.

The lesson that the legal system is sending to manufacturers in this case is clear. Do not recall a risky product and do not publicize its risk. Consumers and doctors who care about product safety should be concerned about this effect of the law.

\section{The Vioxx FIASCO}

Thtil recently, millions of Americans used Vioxx, the arthritis pain reliever produced by the pharmaceutical giant Merck. It began as one of the most successful blockbuster drugs ever, but, soon after its launch, evidence emerged that the drug might be associated with increased cardiovascular risk. In light of this evidence and awaiting a more complete riskbenefit analysis of the drug by the FDA, Merck recalled Vioxx from the market late in 2004. Soon after, Merck's legal nightmare began: it could potentially become the greatest liability episode in pharmaceutical history. Over tenthousand suits have been filed against Merck, 
with more in the pipeline. Two of the first three suits to reach trial ended up with a ruling against Merck. In one case, the jury awarded a single plaintiff $\$ 253$ million.

The legal issues are difficult to resolve, thus it is not clear how individual cases will be decided. In a nutshell, juries are trying to answer a simple question: Was the injury to a given plaintiff caused by the use of Vioxx? Since heart attacks occur for a variety of genetic and lifestyle reasons independent of the drug, how should the law assess the marginal increase in risk arising from the use of Vioxx?

Many observers have voiced the traditional view that imposing a stiff liability on Merck would have a clear deterrent effect on manufacturers of risky and defective products. The message would be clear: "If you leave the product on the market, you will end up paying for it when the defect is revealed." For example, in a recent editorial in The New England Journal of Medicine, the claim was made that "to protect the health of the public...civil penalties should be commensurate with the scale of drug sales" (Psaty and Furberg 2005). At worst, this line of reasoning suggests that costly liability would induce excessive safety. Drugs might be recalled even if their benefit exceeds the harm. But, those drugs that remain on the market are more likely to be safe.

WHAT'S WRONG WITH THE TRADITIONAL VIEW?

Tntuitive and compelling as the traditional argument appears at first blush, it may well be wrong. The magnitude of liability that manufacturers face post recall provides incentives for them to take too little post-sale safety measures and, specifically, to issue too few recalls relative to the social optimum. Even more disturbing, harsh post-recall liability stifles the incentive to monitor and research the risk of products already in use. This concern is particularly acute concerning products that are associated with latent manifestations of harms, such as drugs.

The reason for this counterintuitive effect is the following. Only after a product is launched does the manufacturer receive comprehensive information about the potential harms and risks. Often, this information is not publicly known; in fact, much of it can only be assembled by a sophisticated information collection effort of the manufacturer. The manufacturer recognizes at this interim stage that even if the information turns out to be true and the risks materialize, it would be difficult for the courts to discern whether there is a causal link between the use of the product and the harm victims suffered. For example, was an individual plaintiff's cancer caused by a defendant's carcinogenic product or by a host of other environmental factors? Did the plaintiff's heart attack result from taking Vioxx or from eating greasy burgers? Not only is it difficult for juries to make these determinations, victims rarely know whom to blame. This cloud of uncertainty provides some protection to the manufacturer.

Still, once the manufacturer realizes that the product is dangerous, it expects some liability to emerge. Recalling the product, then, would have the upside of preventing some future harm, thus decreasing some future liability for these prevented harms (liability for past-distributed products can no longer be reduced.) But-and this is the crucial point-recalling the product would have the downside of "bursting the floodgates" and inviting numerous suits from past users, many of which would otherwise not be filed.

What causes this eruption of suits? A recall, 
or other high-profile redesign of a product that causes harm, is taken as a public "confession" on behalf of the manufacturer that the product is harmful. All parties involved "update" their assessment of the harmfulness of the product and of the expected value of a suit. Victims will now believe that it is more likely that their injury resulted from the use of the product and that the manufacturer was negligent in selling them the defective product. Judges are more likely to suspect that the manufacturer knew about the risks all along. Thus, they might allow broad discovery of the manufacturer's paper trails and permit "fishing expeditions" for suspicious emails and the like. Importantly, juries will view the confession as resolving the otherwise murky issue of causation, thus they are more likely to find the manufacturer liable. And, the plaintiff's attorneys-important catalysts in this process-view the public recall announcement as an opportunity to launch a more effective and coordinated legal assault on the publicly vulnerable manufacturer. In fact, recalls have long been the sounding horn for attorneys to race to recruit plaintiffs.

This whole process is illustrated by the
Vioxx case. In the wake of the recall, lawyers have organized coordinated efforts to identify Vioxx users through mass email, 1-800 numbers ("1-800-LAW-SUIT"), and television ads. They coordinated litigation strategies in conventions and other professional circulations, and they "shop" for courts that are reputed to be friendly to tort plaintiffs. A little more than a year after the recall, the number of suits filed was over ten thousand, with close to one-hundred class action suits. Similarly, when another pharmaceutical manufacturer, Bayer, recalled its cholesterol drug Baycol in 2001, the number of suits rose from zero prior to the recall to over fifteen-thousand individual lawsuits within two months. Further, when American Home Products withdrew the diet drug Fen-Phen in 1997 (following a request by the FDA), eighteen-thousand lawsuits were filed!

Surely, if a manufacturer were to leave a dangerous product on the market, some of the latent harms would eventually lead to lawsuits and liability. However, instead of a "tsunami" of lawsuits, as some plaintiff lawyers describe the current phenomenon, liability would trickle lightly, even if steadily. Without the public confession embodied in a high-profile recall, the legal system would be less hospitable to plaintiffs. Plagued by uncertainty over causation and the lack of emotional press coverage, plaintiffs are less likely to succeed. Most victims would not even bother to sue.

Thus, the choice for the manufacturer is clear: recall the product and suffer an eruption of liability for products already sold or remain silent and suffer some ongoing liability over a longer period of time. With the phenomenal scope of the recall-associated liability, it is rational for a manufacturer to leave the product on the market.

\section{THE EFFECTS ON THE DISCOVERY OF RISKS}

T $t$ is bad enough that product liability law creIates this perverse incentive to recall harmful products. Perhaps even more disturbing is the effect on the manufacturer's incentive to research and acquire better information about risk. In our regulatory system, government agencies have limited resources or authority to collect information about products that have already been launched. The manufacturer, then, is the chief actor on whom society relies to gather information and update the pool of 
knowledge. Here, too, the "floodgates" effect of liability hurts, rather than improves, the incentives of the manufacturer to research the risks and to acquire more accurate information. Because the incentive to use the information-even highly accurate information-is distorted, the incentive to acquire the information is also distorted.

Letters commenting on this piece or others may be submitted at

cgi? context =ev

\section{REFERENCES AND FURTHER READING}

Ben-Shahar, Omri, (2006) "How Liability Distorts the Incentives of Manufacturers to Recall Products", Olin Discussion Paper No. 2005-02, University of Michigan Law School

Psaty, B M, Furberg, C. D., (2005) "Editorial, COX-2 Inhibitors-Lessons in Drug Safety", The New England Journal of Medicine, 352, 1133-1135.

$\theta$ 